\title{
It's about time: clocks in the developing lung
}

\author{
Colleen M. Bartman, ${ }^{1}$ Aleksey Matveyenko, ${ }^{2}$ and Y.S. Prakash ${ }^{1,2}$ \\ 'Department of Anesthesiology and Perioperative Medicine and 'Department of Physiology and Biomedical Engineering, Mayo Clinic, Rochester, Minnesota, USA.
}

\begin{abstract}
The discovery of peripheral intracellular clocks revealed circadian oscillations of clock genes and their targets in all cell types, including those in the lung, sparking exploration of clocks in lung disease pathophysiology. While the focus has been on the role of these clocks in adult airway diseases, clock biology is also likely to be important in perinatal lung development, where it has received far less attention. Historically, fetal circadian rhythms have been considered irrelevant owing to lack of external light exposure, but more recent insights into peripheral clock biology raise questions of clock emergence, its concordance with tissue-specific structure/function, the interdependence of clock synchrony and functionality in perinatal lung development, and the possibility of lung clocks in priming the fetus for postnatal life. Understanding the perinatal molecular clock may unravel mechanistic targets for chronic airway disease across the lifespan. With current research providing more questions than answers, it is about time to investigate clocks in the developing lung.
\end{abstract}

\section{Introduction}

The circadian system enables adaptation to environmental stimuli and is evolutionarily conserved (1). In mammals, the suprachiasmatic nucleus (SCN) in the brain provides time cues that coordinate physiological and behavioral functions (e.g., sleep, alertness, eating, hormone levels) $(2,3)$. The SCN is entrained by light (4), although intrinsic SCN clock genes (5) and genomic oscillatory mechanisms also exist (6-10). However, 25 years after the SCN was celebrated as the "master clock," peripheral cellular clocks, i.e., intracellular networks of transcription-translation feedback loops, were discovered in all tissues (11-14). Peripheral clocks are responsive to various synchronizing agents, such as glucocorticoids (15) and adenylate cyclase activators (16), and, in vivo, circadian entrainment strategies such as light-dark cycles or non-photic cues like time-of-day feeding regimens and activity (17). The SCN can synchronize peripheral clocks across tissues and circadian physiological behaviors through neuronal (direct) or humoral (indirect) cues in response to external stimuli (18). Supporting this notion, a novel clock luciferase reporter mouse model established that the SCN was necessary for phase synchronization across tissues (19). However, mechanisms of circadian entrainment between external environment, SCN, and peripheral clocks vary by tissue type. Such heterogeneity underlines potential cell-, context-, and organdependent roles of peripheral clocks. Therefore, it has become critical to understand clock biology and its disruption in the specific context of any organ and its normal function or role(s) in disease.

Pulmonary function is known to vary diurnally in healthy individuals (20). Circadian variations in symptoms and treatment responsiveness for chronic airway diseases such as asthma were reported in the 1970s amid initial studies on clock biology $(21,22)$. Lung molecular clocks, first identified in 1998 in rats

Conflict of interest: The authors have declared that no conflict of interest exists. Copyright: () 2020, American Society for Clinical Investigation.

Reference information: J Clin Invest. 2020;130(1):39-50.

https://doi.org/10.1172/JCI130143.
(23), have since been implicated in adult airway disease pathophysiology. However, clock biology in perinatal lung has received far less attention. While circadian rhythms were long considered irrelevant to the developing fetus given its erratic sleep patterns and lack of external light exposure, peripheral clock biology calls this assumption into question. This Review aims to bridge the gap between the clock and the developing lung to hopefully unravel mechanistic targets for chronic airway disease across the lifespan. With more questions than answers, it is nonetheless time to investigate clocks in the developing lung.

\section{Basics of clock biology}

The core clock oscillatory network (Figure 1) consists of BMAL1 (encoded by ARNTL); CLOCK (CLOCK); PER1, PER2, and PER3 (PER1, PER2, PER3); and CRY1 and CRY2 (CRY1, CRY2). BMAL1 and CLOCK oscillate anti-phase to PERs and CRYs in an approximately 24-hour day. BMAL1 and CLOCK form a DNA-binding complex that transcriptionally regulates PER1, PER2, PER3, CRY1, and CRY2 gene expression via E-box promoter elements. PER1, PER2, PER3, CRY1, and CRY2 proteins form cytoplasmic heterodimers and, following phosphorylation, translocate back to the nucleus to prevent BMAL1-CLOCK complex from regulating downstream targets, including transcription of PER and CRY genes themselves. Two notable nuclear receptors regulate timing and amplitude of BMAL1 and therefore stabilize the clock: Retinoic acid-related orphan receptor- $\alpha(\mathrm{ROR} \alpha)$ binds to ROR response elements (ROREs) in promoters of $A R N T L$, driving BMAL1 expression, while REV-ERB $\alpha$ (NR1D1) competes with ROR $\alpha$ at ROREs. Furthermore, the NR1D1 promoter contains an E-box element and ROREs, which drive gene expression under control of BMAL1-CLOCK (1). In addition to these core components, clock stabilization, timekeeping, and entrainment can involve other signaling molecules. For example, cAMP and $\mathrm{Ca}^{2+}$ target the feedback transcriptional loop via cAMP response elements (CREs) in Per1 and Per2 promoters to modulate clock amplitude, phase, and period (16, 24-26). In support of this notion, in the mouse SCN, cAMP/Ca ${ }^{2+}$ signaling is elevated 
A

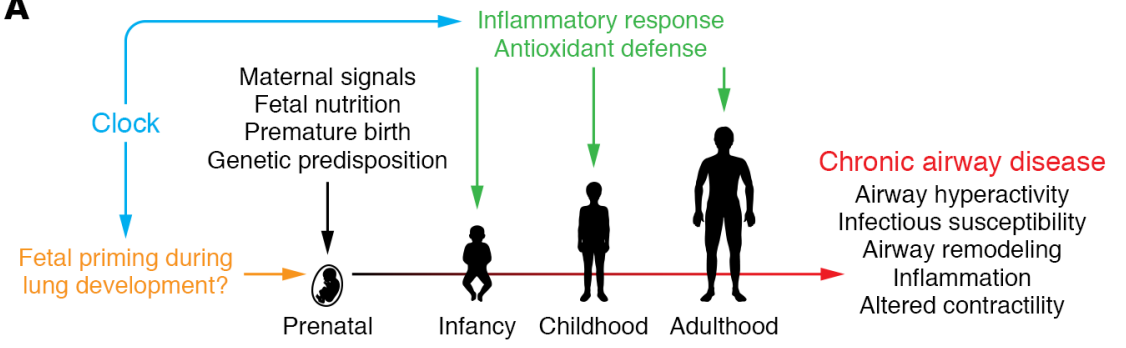

B

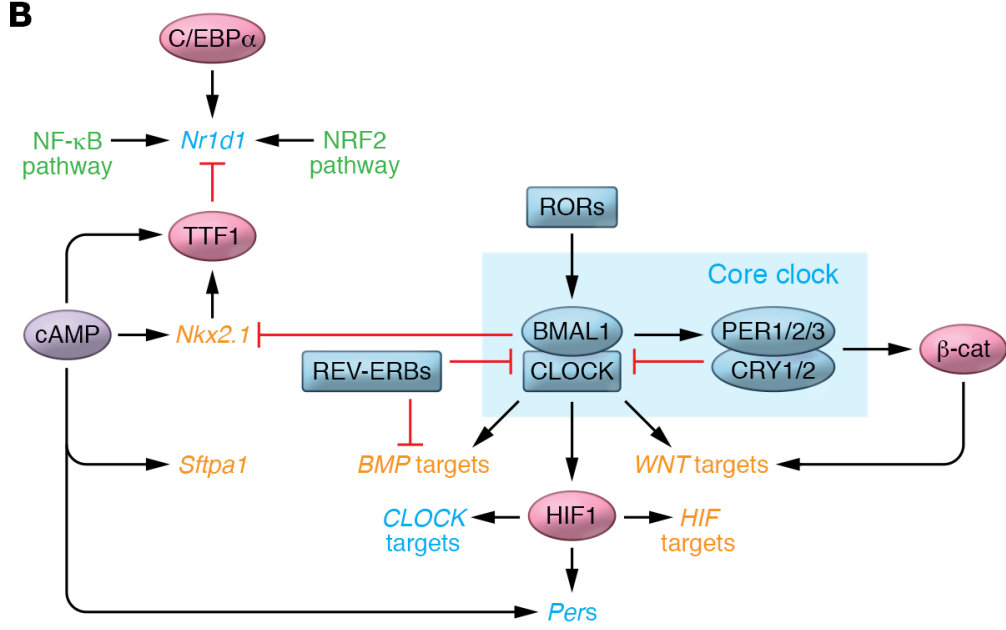

Figure 1. Factors during fetal development and throughout life that drive progression of chronic airway disease and potential role of the clock's transcription-translation 24-hour feedback loop. (A) During fetal development, maternal signals (e.g., stress hormones, hormonal factors), fetal nutrition, premature birth, genetic predisposition, and perhaps the clock influence development of chronic airway disease. Additionally, environmental factors, infections, and the clock during postnatal life and during adulthood further drive airway disease, defined by airway hyperreactivity, infectious susceptibility, airway remodeling, inflammation, and altered contractility. (B) The relationship between the clock and developmental pathways may prime the fetal lung for postnatal life. BMAL1 and CLOCK drive expression of PER and CRY genes. PERs and CRYs, which are posttranslationally modified in the cytoplasm, heterodimerize and translocate back to the nucleus, where they inhibit the BMAL1-CLOCK complex, thereby suppressing their own gene expression. This pattern occurs such that BMAL1 and CLOCK peak during the nighttime, while PERs and CRYs peak in the morning. The nuclear receptors REV-ERBs inhibit BMAL1 (Arntl) gene expression, while RORs drive Arntl gene expression. Key pathways involved in fetal lung development have a bidirectional relationship with the molecular clock. Core clock components are shown in blue, lung developmental pathways in orange, secondary messengers in purple, non-clock proteins in red, and inflammatory or antioxidant pathways in green. Genes and gene targets are styled in italics.

around dawn and decreases later in the day $(16,24,27,28)$. Overall, complex regulation of genes/proteins involved in mediating and modulating intracellular clocks allows for substantial dynamics and heterogeneity in cell- and context-specific fashion, and conversely points to multiple paths for dysfunction.

Emerging data from multiple cell systems are providing insights into how core clock components regulate downstream non-clock genes and proteins (29-33). Regulation of clock-controlled genes is also cell- and context-specific (34-36). Nonetheless, there are key targets potentially relevant to the lung (as described below). For example, BMAL1-CLOCK can modulate HIF-1 $\alpha$ - and BMPregulated genes, while REV-ERB $\alpha$ negatively regulates BMP target genes. CRY1 and CRY2 modulate $\beta$-catenin nuclear localization and thus indirectly drive Wnt target genes, while nuclear localiza- tion of BMAL1-CLOCK facilitates direct modulation of Wnt-sensitive genes. Within these contexts, it should be recognized that clock-controlled genes can be independently regulated by pro- and antiinflammatory pathways such as NF- $\mathrm{KB}$ or NRF2 that also happen to impact clock genes themselves, establishing a multidirectional regulatory system (Figure 1 ).

\section{Clocks in the adult lung}

Peripheral clock oscillations synchronize to signals from SCN through vagal innervation (ref. 37 and reviewed in refs. 38, 39). Lung physiology exhibits functional circadian rhythmicity in normal individuals, and a growing body of evidence suggests that clock disruption profoundly affects lung function and disease pathophysiology (refs. 39-46 and Table 1). Animal models with genetic deletion of clock genes support a functional role for lung clocks (Table 2). Jet-lag models (altered light-dark cycles), cigarette smoke, and viral or bacterial infections have been established as deleterious to lung clocks (43, 47-50). The relationship between clock disruption and chronic airway disease (chronic obstructive pulmonary disease, asthma, fibrosis) in adults reveals key mechanisms and provides insight into potential chronotherapeutic strategies (treatment based on endogenous circadian biology and time-ofday variation in pharmacological efficacy; ref. 51). Tables 1 and 2 depict only a fraction of the complex and diverse nature of lung clocks and emphasize the importance of precise cell-specific clock regulation.

With emerging recognition of clocks in adult lung physiology and disease, several questions become relevant for lung development and perinatal diseases:

A. When do lung clock pathways appear during development?

B. How does maternal circadian rhythmicity regulate fetal clocks and lung development?

C. What role, if any, do clocks play in the embryonic lung, which does not have a respiratory function in utero?

D. What is the functional status of lung clocks at birth, and do they play a role in perinatal and postnatal lung growth? Indeed, is an underdeveloped clock important in the context of premature birth and subsequent postnatal growth?

E. What effects do perinatal insults such as infection, inflammation, or iatrogenic factors in the context of ICU care of premature infants such as light, oxygen, and mechanical ventilation have on postnatal lung growth?

F. Are there heterogeneity and synchrony in clocks across lung cell types? 
Table 1. Clocks in the lung: establishing a relationship between circadian rhythms and lung structure/function in adults

Normal lung function and the clock

Reference

No disease/healthy individuals

Circadian fluctuation in lung function: FEV1, FVC, PEF, and inflammatory responses exhibit a circadian pattern (lower

158,159 during the night, higher during the day)

\section{Circadian clock disruption and the lung}

Circadian clock disruption (gene/protein expression, amplitude, period, or phase)

Clocks and fibrosis

Severe Asthma Research Program

RSV Bronchiolitis in Early Life Study

Clock and lung disease via antioxidant defense pathway

Clock and lung disease via inflammatory response
Immune-inflammatory responses

$41,44,47,160,161$

DNA damage/repair

162

Stress-induced premature senescence

163

Oxidative stress response

46,164

Cellular proliferation

$165-167$

$\left[\mathrm{Ca}^{2+}\right]_{\mathrm{i}}$

168,169

Cell cycle

Stem cell differentiation

$96,170-172$

Mitochondrial dynamics

173

Energy metabolism

$33,174,175$

\section{Lung disease and the clock}

Symptoms more severe during the night and early morning hours

Asthmatics exhibit circadian variation in responsiveness to treatment, while symptom severity tracks with circadian

21, 176-181 disruption

In a mouse model of COPD, cigarette smoke reduces NAD-dependent deacetylase sirtuin 1 (SIRT1) activity in the lungs. SIRT1 maintains an established role with the clock by binding - in a circadian fashion - to BMAL1-CLOCK, subsequently driving PER2 deacetylation and degradation. Cigarette smoke-driven SIRT1 reduction therefore enables hyperacetylation of clock proteins, altered clock oscillation, and dampened transcriptional activity at E-box promoters.

BMAL1 is implicated in the profibrotic response: In lung epithelial cells and lung fibroblasts in vitro, TCF- $\beta 1$ increased expression of BMAL1, an effect mimicked in an in vivo mouse model of pulmonary fibrosis. Additionally, ARNTL knockdown in lung epithelial cells altered TCF- $\beta 1$ signaling and subsequent epithelial-mesenchymal transition, while ARNTL knockdown in lung fibroblasts prevented differentiation.

In data sets from the Severe Asthma Research Program analyzed by an independent research group, asthmatic adults undergoing bronchial brushings exhibited a significant decrease in the core clock genes ARNTL, PER2, and NR1D1 and an increase in expression of CLOCK compared with healthy adult volunteers.

Nasal wash samples from infants with respiratory syncytial virus (RSV Bronchiolitis in Early Life Study) revealed that infants with RSV had significantly decreased ARNTL gene expression compared with healthy controls and a trending reduction in PER2 and NR1D1, albeit not significant. Incorporating downregulation of ARNTL expression in human asthmatics with the BMAL1-knockout mouse models in which lack of BMAL1 exacerbates asthma-like phenotypes highlights the crucial role of the clock in asthma pathophysiology and suggests another therapeutic strategy.

Clock linked to pathogenesis of pulmonary diseases through its regulation of NRF2, whose activation is driven by oxidative stress. NRF2 promoter contains an E-box element under circadian control; antioxidant genes involved in the NRF2 antioxidant defense pathway were found to be expressed rhythmically in the mouse lung.

At the time of day when NRF2 levels are lowest, there is greater fibrosis in the bleomycin mouse model, while mice deficient in Clock have significantly reduced NRF2 levels, higher ROS/oxidative damage, and increased fibrosis with bleomycin.

NF- $\kappa B$ subunits are targeted by SIRT1 deacetylase activity, which suggests a role for SIRT1 and the clock in the inflammatory response. SIRT1 activation and what is now being termed the SIRT1-BMAL1 pathway may serve as a therapeutic target in $\mathrm{COPD}$, bridging the lung clock and inflammatory response.
47 47
G. Does modulating clocks in developing lung limit the impact of detrimental factors in the perinatal period to improve outcomes for lifelong diseases?

\section{An overview of fetal lung development}

Understanding of lung development is largely derived from mouse models that are amenable to genetic manipulation and have a short period of embryonic lung growth (10-14 days). In spite of structural differences between mouse and human lung $(52,53)$, molecular factors coordinating lung developmental stages overlap $(52,53)$. Briefly, the endodermal transcription factor NKX2.1 (TTF1) initiates lung development (embryonic stage: E9.5-E12.5 in mice, 4-7 post-conception weeks [pcw] in humans), dependent on mesodermal Wnt signaling and inhibition of SOX2 (NKX2.1 inhibitor) by BMP4 (54-56), to establish ventral-dorsal patterning of the anterior foregut. Branching morphogenesis generates airways via epithelial FGF, SHH, and BMP4 (57-60), while SOX2 or SOX9 and ID2 drive proximal or endodermal progenitors, respectively, to give rise to multiple airway cell types $(61,62)$ (pseudoglandular stage: E12.5-E16.5, 5-17 


\section{Table 2. Clock animal models in lung physiology}

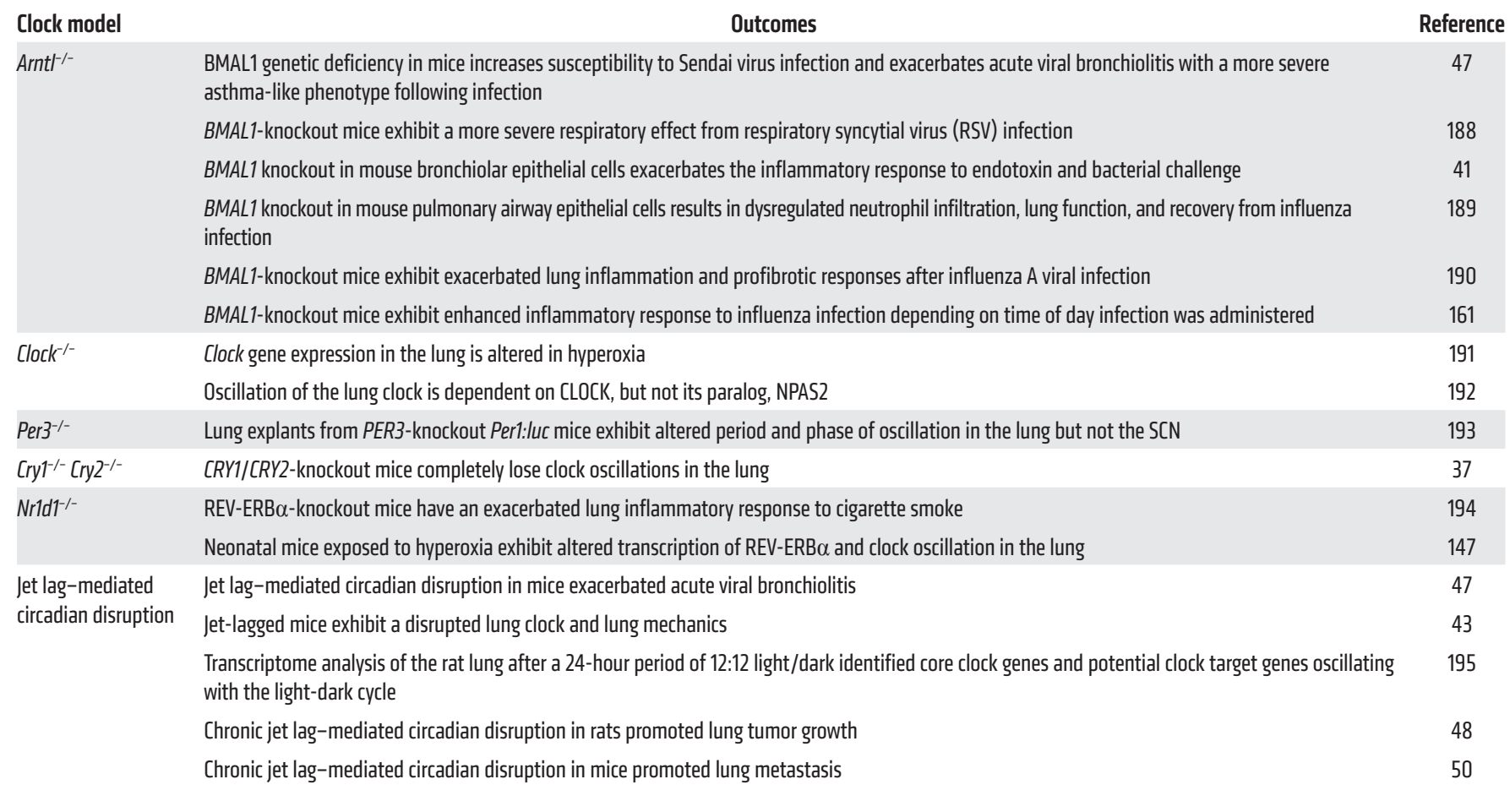

pcw). Clusters of epithelial sacs begin to form as the branches narrow (canalicular stage: E16.5-E17.5, 16-26 pcw; and saccular stage: E17.5-P5, 26-36 pcw), fully maturing into alveoli (alveolarization stage: P0-P14, $36 \mathrm{pcw}-3$ years $)(52,53)$.

The mouse model is advantageous for understanding neonatal/ pediatric human disease (63-66). The mouse postnatal day 0 (P0) lung roughly correlates to that of a premature infant at about 32 weeks gestation, a 1-week-old mouse to a full-term newborn, and a 3-week-old mouse to an approximately 3-year-old child (Figure 2) (53). Thus, late-embryonic and neonatal mice offer the opportunity to explore perinatal insults in the context of premature birth, whereas post-weaning mice enable exploration of the effects of initial insults on subsequent lung structure and function in the context of pediatric disease.

\section{Clocks and the embryo}

The contribution of clocks to development is largely unknown, but characterizing the emergence of clocks throughout gestation may help us understand potential functional patterns. Arntl transcripts were initially considered to be present in unfertilized mouse eggs and the 2-cell and 16-cell stages (67). A more comprehensive study showed a peculiar pattern of the clock genes Per1, Per2, Per3, Cry1, Cry2, Clock, and Arntl: while these genes were all expressed in the unfertilized egg and zygote (albeit at different levels), some transcripts disappeared at the 2-cell, 8-cell, and 16-cell stages, with complete restoration at the blastocyst stage (68). We can only speculate on the teleological rationale for this pattern of expression and disappearance. In vitro studies indicate that the pattern of emergence and disappearance continues throughout fetal development. Mouse embryonic stem cells from the late blastocyst stage lack a functional oscillatory clock. Differentiation of embryonic stem cells was sufficient to establish a clock rhythm, and strikingly enough, reprogramming differentiated cells to induced pluripotent embryonic stem cells triggered disappearance of the clock (69-71).

It is important to consider that absence of clock oscillation or synchrony does not imply absence of clock gene expression or functional relevance. Lack of synchrony during early stages of development and appearance upon differentiation strongly highlight a potential role of the clock in cell type specificity and differentiation. It is plausible that synchrony in the early embryo would inhibit differentiation by preventing various signals from targeting multiple differentiation pathways from progressing.

Evidence for clocks in later embryonic development derives from somitogenesis, a systematic process that establishes bilateral symmetry through sequential addition of somite pairs (mesodermal cells) on either side of the notochord along an anterior-posterior axis (beginning E8 in mice, 3 pcw in humans). This body axis segmentation lays the foundation for dermatomes, myotomes, and sclerotomes (72-74). Somitogenesis is under precise temporal control, orchestrated by rhythms of developmental signaling pathways (e.g., Notch, Wnt, and FGF). Before discovery of molecular clocks, the "clock and wavefront" model (75) hypothesized that an oscillator in presomitic mesodermal cells was halted by a wavefront moving posteriorly along the body axis, with wavefront timing corresponding to somite size and number (75). Somitogenesis can be viewed differently in the context of molecular clocks and oscillations. Notch transcription factors oscillate in concordance with segmentation periodicity $(76,77)$, as noted 


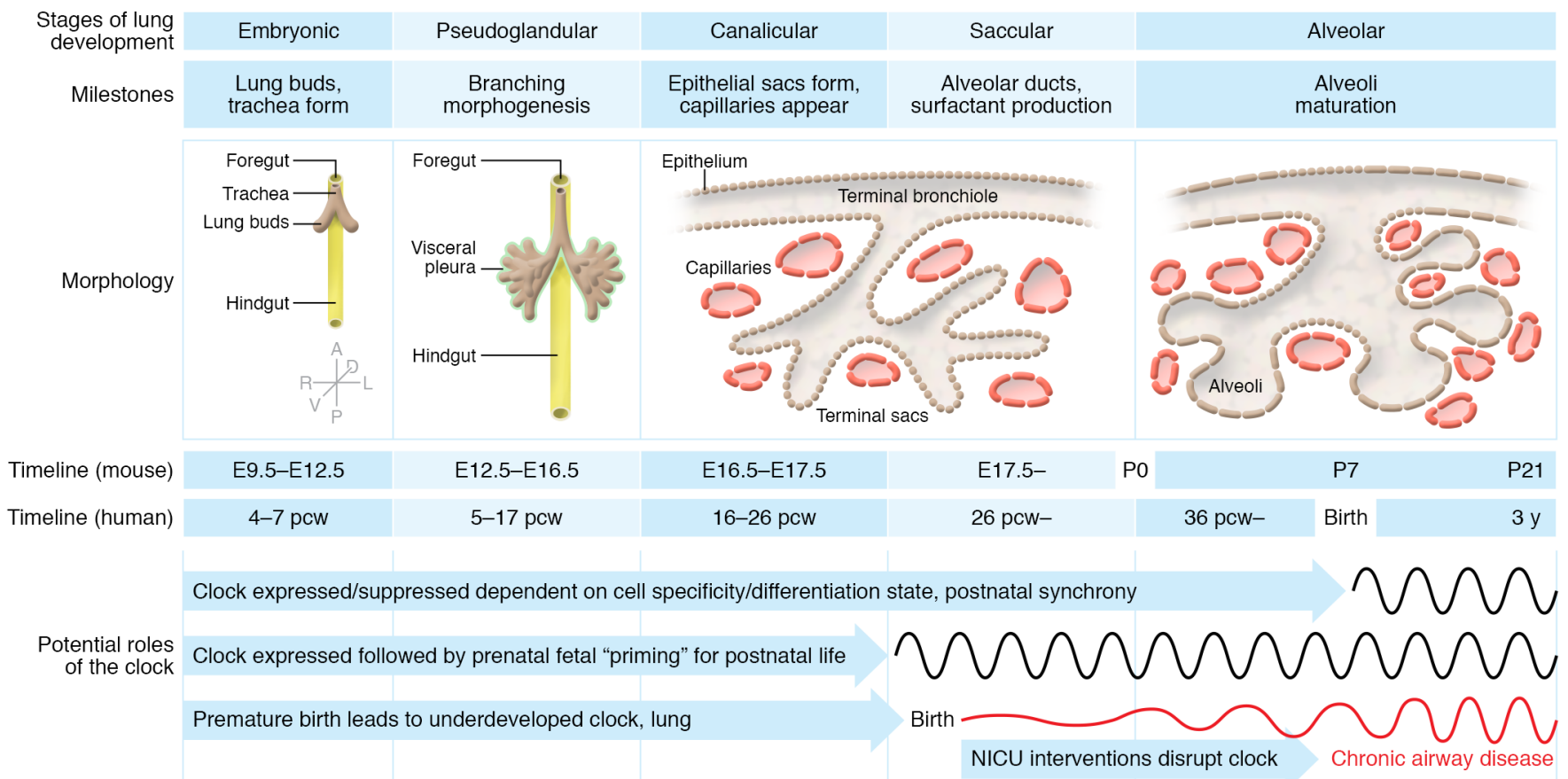

Figure 2. Timeline of five stages of lung development in mice and humans and the potential role of the clock. The five milestones of lung development are embryonic (formation of lung buds), pseudoglandular (branching morphogenesis), canalicular (formation of epithelial sacs and appearance of capillaries), saccular (production of alveolar ducts and surfactant protein), and alveolar (maturation of the alveoli). Mouse stages are represented in embryonic (E) or postnatal $(P)$ days, and human stages are represented by post-conception weeks $(\mathrm{pcw})$. One potential role of the clock includes regulation of clock gene expression dependent on cell type specificity and differentiation during developmental stages with coordinated oscillations postnatally. Alternatively, the clock may be involved in prenatal priming for adaptation to postnatal life. In the latter model, insults like premature birth and necessary interventions deleteriously affect the clock and drive progression of chronic airway disease.

in mouse embryos (78-80). Per1, Per2, Arntl, Clock, Cry1, and Cry2 are expressed in developing Xenopus somites, and BMAL1 in particular mediates somitogenesis $(81,82)$. Furthermore, BMAL1-CLOCK regulates myogenesis by transcriptionally targeting the muscle differentiation factor $M y o D(83,84), C R Y 2$ post-transcriptionally regulates myogenic differentiation (85), and REV-ERB $\alpha$ inhibits myogenesis through Wnt (86). While these data show the presence of clocks at various stages of development, what are less clear are the teleological and functional implications of intermittent clock gene expression during different phases of embryogenesis, and the coordination of clock genes in orchestrating organogenesis.

\section{Clocks and fetal lung development}

Interestingly, clock oscillation can be detected in utero at time points that match the earliest stages of embryonic lung development and into the pseudoglandular stage (E12.5-E16.5). For example, in pregnant rats carrying a Per1 luciferase reporter activity transgene, Per1:luc bioluminescence appeared in the fetus by E9 with a striking increase at E10 toward the maternal active phase (evening). Bioluminescent measurements at dawn and dusk revealed differences in time-of-day Per1:luc from E13 to E22, with overall Per1:luc activity increasing logarithmically from E10 to E22 (87). Notably, this study examined the whole embryo, and not the lung per se, but it does suggest the possibility of lung clocks during early critical developmental periods.

Expression of NKX2.1/TTF1 is critical for early fetal lung development and regulation of surfactant protein. NKX2.1 is increased by glucocorticoids and cAMP in human fetal alveolar type II cells (88), and by TGF- $\beta$ in E10 mouse epithelial cells (89), while proinflammatory TNF- $\alpha$ inhibits $N K X 2.1$ expression in human adenocarcinoma cells $(90,91)$. While it is unknown whether fetal TTF1 is under control of the clock, reports in other tissues have linked the two. Nkx2.1 in the rat brain preoptic area is modulated by the light-dark cycle, while in GT1-7 cells (a neuronal cell line derived from murine hypothalamus), BMAL1-CLOCK represses Nkx2.1 promoter activity and CRY1 activates $N k \times 2.1$ transcription (92). BMAL1-CLOCK-mediated suppression of $N k \times 2.1$ is also reported in rat C6 glioma cells (93). Furthermore, TTF1 inhibits Nr1d1 transcription in GT1-7 cells (92). A genome-wide analysis found a differential role for TTF1 gene targets in early versus late mouse lung development with two clock pathways of note: at E11.5, Cry2 expression positively correlates with TTF1, while at E19.5, Clock expression positively correlates with TTF1 (94).

cAMP may be an important aspect of embryonic clock development. cAMP modulates clock properties via CREs in Per1 and Per2 promoters (16), regulates NKX2.1, and regulates TTF1's interaction with CREB to subsequently increase transcription of its downstream targets (95). In the developing fetal lung, cAMP signaling regulates surfactant protein A gene expression in type II cells (95). These loosely linked data suggest relationships between clock, cAMP signaling, NKX2.1/TTF1, and developing lung that need to be better delineated in the context of actual changes in lung structure and function, as well as cellular and temporal patterns. 


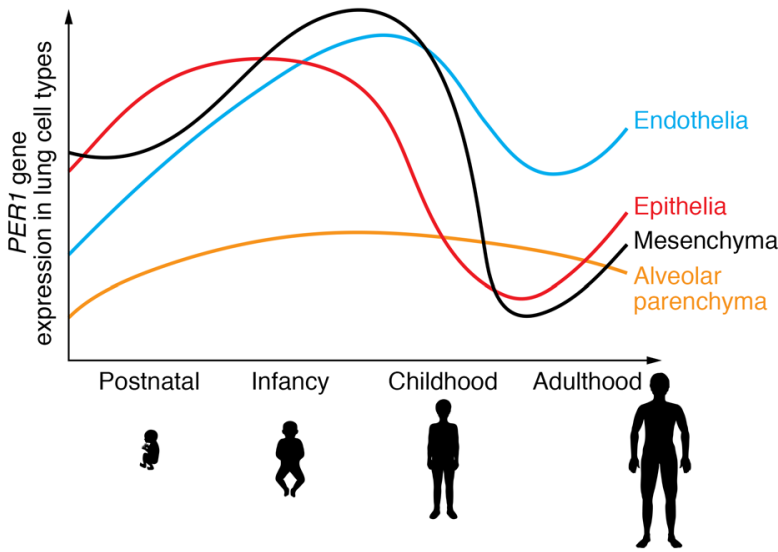

Figure 3. Leveraging LungMAP for a glimpse into lung clocks. Data from the National Heart, Lung, and Blood Institute's LungMAP consortium (www.lungmap.net) provide glimpses into the spatial and temporal dynamism of clock gene expression in the postnatal human lung, a more relevant time period in the context of healthy growth and perinatal/pediatric disease. Clock genes such as PER1 appear to be substantially expressed in the early postnatal period, while showing considerable variation in different lung cell types toward adulthood. Genes such as PER1 could be appealing to explore in the context of lung growth, responses to insults like oxygen or inflammation in prematurity, and initiation of chronic lung diseases. It may also be important to consider whether differential expression in epithelial versus mesenchymal cells is relevant to specific disease progression.

While a myriad of signaling pathways have been implicated in different aspects of embryonic lung development, four key pathways may be relevant in terms of clocks: FGF, BMP, Wnt, and SHH. In nonpulmonary tissues, the clock has been implicated in Wnt and BMP signaling pathways. For example, Wnt regulates clocks in the Drosophila intestinal stem cell niche (96), and CRY1 regulates adipogenic differentiation in mouse 3T3-L1 embryonic fibroblasts (97). In preadipocyte 3T3-L1 cells in vitro, proliferation and components of the Wnt signaling pathway are under transcriptional control of CLOCK (98). Additionally, CRY1 can regulate osteoblast differentiation in human osteosarcoma cells via Wnt signaling (99). In human aortic endothelial cells, loss of BMAL1 drives endothelialmesenchymal transition through increases in BMP signaling and ROS accumulation (100). Furthermore, promoters of Bmp genes have E-box elements for clock control, and in uterine endometrial stromal cells, REV-ERB $\alpha$ transcriptionally represses Bmp expression while dampening of clock upregulates BMP-encoding genes (101). These many disparate data regarding clock elements in other systems may provide important insights into lung development, given known roles of both Wnt pathways (102-104) and BMP signaling (105-108) in this process. Relationships between clock and other critical elements such as FGF or SHH remain to be established in any organ system, but are exciting areas to investigate in the context of understanding clock regulation of lung development.

Another important factor to consider is the link between clocks in the fetal lung and hypoxia. Fetal development occurs in a relatively hypoxic environment in utero, which is critical during pseudoglandular and canalicular stages (109). In lowoxygen environments, HIFs are essential transcription factors for embryonic development, as evidenced by embryonic lethality of Hifla-knockout mice by E11 (110). HIFs regulate downstream pathways involved in energy metabolism, proliferation, angiogenesis, extracellular matrix formation, and apoptosis $(111,112)$. Recent studies have identified yet another bidirectional relationship between HIF-1 $\alpha$ and the clock that suggests a potential link in utero: In mice treated with DMOG, a drug that stabilizes HIF-1 $\alpha$, BMAL1 drives Hif1a gene expression (113). Additionally, in U2OS human bone osteosarcoma epithelial cells, HIF-1 $\alpha$ is bound to the PER2 promoter, which regulates its expression (113), while in mouse fibroblast cells, Nr1d1, Per1, and Per 2 are induced by HIF-1 $\alpha$ stabilization (113). Furthermore, HIF-1 $\alpha$ dimerizes with BMAL1 with substantial overlap of downstream target genes (114). Conversely, mouse skeletal myotubes lacking BMAL1 exhibit reduced Hifla expression and increased HIF-1 $\alpha$ turnover, while Per2:luc oscillatory activity is dependent on HIF- $1 \alpha$ stability (115). Lastly, an elegant study found diurnal variation in oxygenation in blood, brain, and kidney in adult mice, with kidneys displaying a different time-of-day peak of HIF- $1 \alpha$ nuclear localization compared with brain. In vitro experiments using Hepa-1c1c7 (murine hepatoma) and NIH 3T3 (murine fibroblast) cells and rhythmic $\mathrm{O}_{2}$ exposures (12 hours $5 \% \mathrm{O}_{2} / 12$ hours $8 \% \mathrm{O}_{2}$ ) "reset" clock oscillation, a phenomenon dependent on HIF-1 $\alpha$ (116). While these studies were primarily done in nonfetal models or in cell lines, one study did use SCN slices from postnatal mice at P3-P6 carrying a Per2:luc reporter; when anoxia was mimicked ex vivo, the period of clock oscillation was lengthened and amplitude diminished (113). Taken together, these studies suggest that $\mathrm{O}_{2}$ is a signal to the fetal clock during development, and oscillations in fetal $\mathrm{O}_{2}$ may prime the fetus for postnatal life. The precise role of hypoxia and the clock during lung development can only be speculated, but previous work suggests that oxygen exposure may regulate the pattern of clock emergence. On the other hand, rat pups born to mothers exposed to hypoxic gas $\left(10 \% \mathrm{O}_{2}, 90 \% \mathrm{~N}_{2}\right)$ when their fetuses were at $\mathrm{E} 5$ have profound behavioral and locomotor abnormalities, phase advancement, and failed entrainment to new light-dark cycles (117). Conversely, clock oscillations are altered by hyperoxia exposure in neonatal mice through REV-ERB $\alpha$ (118). Thus, the timing and extent of oxygen exposure may also be a critical driver of lung development.

\section{Maternal cues to the fetal lung}

Some insights regarding maternal cues in fetal clock development are provided by behavioral differences in offspring of precocial animals (born at an advanced stage of independence, e.g., monkeys, sheep) versus altricial animals (born at an underdeveloped stage, e.g., rats, hamsters, mice). Humans are a unique blend of precocial in many aspects of bodily form but neurologically and behaviorally altricial. In recognized precocial mammals, there are distinct fetal physiological rhythms in heart rate, breathing, movement/activity, and plasma cortisol (119-122), suggesting that clock develops prenatally. In altricial mammals, physiological rhythms in terms of behavior, temperature, activity, and corticosterone may be more substantially impacted postnatally depending on the length of gestation: rhythms may be established in utero of humans with longer gestation times, whereas species with shorter gestation times are still establishing rhythms postnatally. Alternatively, emergence of rhythms may depend on SCN development: in precocial species, the 
fetal SCN is developed by midgestation, but it begins to form around E14 in altricial species, completing development around birth (123). However, in studies using Per1:luc mouse models, luciferase activity appeared before the fetal SCN develops (87), suggesting that peripheral fetal clocks emerge independent of central clock signals. Additionally, the maternal SCN may be regulating the fetal clock before development of a functional fetal master clock. In fact, studies in which rat or hamster maternal SCN was ablated support the notion of an endogenous clock established by the fetus itself, synchronized to the maternal SCN (124-126). Additionally, these studies suggest that clock synchrony with maternal SCN during development can dictate postnatal physiological rhythms (124-126). More recent studies found that heterozygous mouse pups from mothers harboring double knockouts of either Per 1 and Per 2 or Per 2 and Cry 1 lacked activity rhythms compared with wild-type littermates (126). These data support the concept that the fetal clock develops endogenously, not through the mother, and that the maternal SCN serves to entrain/signal/synchronize the fetus.

How does the maternal SCN signal and entrain the fetal clock? Candidates include maternal feeding and endocrine signals such as melatonin, glucocorticoids, and other hormones. Melatonin is considered a synchronizing signal for the fetal clock, as demonstrated by exogenous melatonin rescuing rhythmicity in pups born to hamsters in which the SCN was ablated (127). Additionally, the fetal adrenal clock can be manipulated by maternal light exposure; suppression of maternal melatonin by light results in complete loss of fetal BMAL1 and PER2 adrenal oscillations, which are rescued by exogenous melatonin (128).

Glucocorticoids exhibit circadian rhythmicity, reaching peak levels in the morning in humans. This rhythmicity stems from the SCN and the hypothalamus-pituitary-adrenal axis, leading to a circadian pattern of glucocorticoid secretion in a clock-dependent manner $(129,130)$. Glucocorticoids serve as an entrainment signal to peripheral clocks, and circadian disruption can disrupt glucocorticoid oscillations and therefore downstream, peripheral cellular functions (131). Thus, glucocorticoids could be one mechanism by which the fetus entrains to the maternal SCN, and may additionally explain how the fetal lung begins receiving a clock-stimulating signal. The glucocorticoid receptor is expressed in fetal lung during early gestation and drives production of surfactant-associated proteins, cell maturation/differentiation, and lung morphology $(132,133)$. However, the placental glucocorticoid barrier becomes more robust, with reduced maternal glucocorticoids in fetal circulation (134), as the fetus approaches term, and other entrainment mechanisms may become ascendant, e.g., $\mathrm{O}_{2}$. Notably, glucocorticoids are administered to women at risk of preterm delivery to accelerate fetal lung development, while some premature infants receive glucocorticoids to prevent the development of lung disease. Overall, given the established ability of glucocorticoids to entrain peripheral clocks (135), the timing/pattern of glucocorticoid signaling during lung development and growth becomes worthy of investigation.

\section{Fetal origins hypothesis meets the clock}

In the 1990s, a "fetal origins hypothesis" postulated that in utero development programs the fetus for lifelong health versus future disease, regardless of health status at birth $(136,137)$. This notion implies that external factors experienced as an adult (e.g., diet, exercise, cigarette smoke, sleeping habits) may not be the sole determinants of disease. Thus, inadequate priming during fetal development can suppress latent effects on disease progression. Numerous epidemiological studies have linked factors such as low birth weight, nutrition, or stress with coronary artery disease, hypertension, obesity, insulin resistance, cancer, and other chronic diseases (138). The role of the clock in fetal development initially did not receive much attention because animal models lacking clock genes are not embryonic lethal and do not show striking morphological changes. However, the effects of clock knockouts are evident later in life. For example, BMAL1-knockout mice are visually similar to their littermates at birth but show impaired growth and weight gain around 16-18 weeks of age (139), while adults are infertile (140). BMAL1-deficient mice exhibit multiple symptoms of premature aging and increased ROS in several tissues (139), which can be reversed with $N$-acetyl-L-cysteine (141), suggesting that BMAL1 modulates ROS homeostasis. While these studies used whole-body conventional knockout mice, a pivotal study dissociated the role of BMAL1 during embryogenesis from BMAL1 disruption later in life with rather surprising findings: mice with intact BMAL1 during fetal development but lacking BMAL1 in adulthood did not display the same premature aging, indicating that the timing/ pattern of BMAL1 expression is important to organismal health. Indeed, mice lacking BMAL1 in both embryogenesis and adulthood exhibited altered lifespan, fertility, body weight, and blood glucose levels as well as age-dependent arthropathy. However, the presence of BMAL1 during fetal development (deficient only in adulthood) rescued these phenotypes (142). These data strongly suggest that BMAL1's function during fetal development has effects later in life. Other clock genes may also have a role in embryogenesis, priming the fetus through development and setting the stage for health versus disease throughout life (Figure 1).

\section{Clocks and the neonatal lung}

Immediate and efficient transition of the lung to extrauterine life is critical for postnatal survival. This involves coordinating clearance of fetal lung fluid with increased pulmonary blood flow and decreased pulmonary vascular resistance, secretion of surfactant, breathing mechanics, and metabolic adaptation to increased oxygen exposure (143). Maladaptation (as occurs in early birth) runs a high risk of inflammation and oxidative stress in lungs prematurely exposed to normoxia and the extrauterine environment. Data in other cell systems suggest that the clock is bidirectionally linked to immune responses and ROS regulation, raising the question of whether the clock is also involved in the fetal-to-neonatal transition, and additionally whether lack of a functional clock plays a role in responses of the premature lung.

REV-ERB $\alpha$ may be a key connection between the clock and neonatal lung. Abundantly expressed in adult lung (144), REV-ERB $\alpha$ may be regulated by oxidative stress, as evidenced by downregulation of lung Nr1d1 in adult mice exposed to cigarette smoke (145). Multiple studies show the intersection between oxidative stress, inflammation, and REV-ERB $\alpha$ in neonatal lung. Initial reports identified hyperoxia-induced $\mathrm{NF}-\mathrm{\kappa B}$ activation in neonatal mouse lungs (but not in adult) that protected against hyperoxia-induced 
lung injury via inhibition of apoptotic pathways (146). Additional in vitro studies in neonatal mouse lung-derived fibroblasts and in

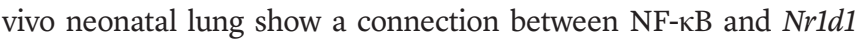
(147). Mouse lung Nr1d1 mRNA expression increases from P1 to P21 and remains elevated in adults. Additionally, hyperoxia-induced increases in neonatal lung Nr1d1 levels are exaggerated in the absence of p50 NF- $\mathrm{kB}$ subunit (147). The Nr1d1 promoter contains not only an NF- $\mathrm{kB}$-binding site, but also an NRF2-binding site. Inflammatory stimulus via TNF- $\alpha$ results in NF- $\mathrm{NB}-$ mediated reduction in Nr1d1 expression, while hyperoxia-induced oxidative stress upregulates Nr1d1 in an NRF2-dependent manner (147). Importantly, in neonatal mouse lung fibroblasts, hyperoxia-mediated oxidative

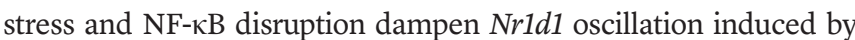
serum shock (147). Furthermore, hyperoxia increases expression of the transcription factor C/EBP $\alpha$ in neonatal mouse lung (148), essential for fetal maturation of lung epithelium and surfactant production (149). C/EBP $\alpha$ was also identified as a regulator of postnatal alveolar epithelial cell proliferation and differentiation in hyperoxia (148), with studies in other cell types showing PER2 and NR1D1 as its transcriptional targets $(150,151)$. However, the link between C/ $\mathrm{EBP} \alpha$ and the clock in the neonatal lung is not yet established.

Overall, emerging studies strongly suggest that oxidative stress and inflammation regulate oscillation of at least REV-ERB $\alpha$, but the relationships (likely bidirectional) between lung responses to perinatal insults such as hyperoxia or inflammation and other key clock drivers such as BMAL1, PERs, and CRYs are unknown. Indeed, if REV-ERB $\alpha$ is modulated by oxygen or inflammation and drives lung cell phenotype, then it is likely that other clock genes are both mediators and modulators of early postnatal lung growth or, at the least, become important in the context of insults. Notably, these relationships are being considered in the broad context of "the lung," but cellular heterogeneity in clock gene expression, oscillatory patterns, and functional roles likely exists and needs investigation.

\section{Harnessing LungMAP to explore developmental clock patterns}

Given the many technical and interpretive limitations in dissecting out the when and how of clocks in the developing lung, insights can be gained from pilot studies mapping spatiotemporal patterns of lung development and growth. Here, the National Heart, Lung, and Blood Institute's LungMAP consortium (http:// www.lungmap.net) (152) is particularly appealing, given its focus on both prenatal and postnatal time points. For example, LungMAP data sets from mouse and human RNA sequencing after laser capture microdissection of alveolar parenchyma, or data from cell sorting for endothelial, epithelial, mesenchymal, and immune cells, allow visual assessment of spatiotemporal patterns in expression of core clock genes. Such assessments show that PER1, $C R Y 2, A R N T L$, and CLOCK expression does occur at key prenatal and postnatal developmental points (with the understanding that additional genes and regulators may also be dynamically involved) (Figure 3). While more in-depth analyses are necessary, this initial evidence leads to intriguing questions:

A. Are these genes oscillating in expression even within the fetal lung, and if so, does the timing of acquisition of tissues (and subsequent gene analysis) matter?
B. If there are temporal variations, are they intrinsically synchronized, or obtaining cues from maternal patterns?

C. Do clock genes or their patterns matter to lung growth, i.e., are clock genes functional?

D. Are there species differences in clock gene expression, particularly in perinatal temporal patterns and functionality in altricial versus precocial species?

The LungMAP data provide glimpses into the spatial and temporal dynamism of clock gene expression in the postnatal lung, perhaps a more relevant time period in the context of healthy growth and perinatal/pediatric disease. Clearly, some clock genes, such as PER1, appear to be important in the early postnatal period, and could be appealing to explore in the context of lung growth, responses to insults such as oxygen or inflammation in prematurity, and initiation of chronic lung diseases. Here, it may also be important to consider whether differential expression in epithelial versus mesenchymal cells is relevant to specific disease progression. Conversely, the relative stability (or at least lack of reduction) of CLOCK or CRY2 suggests that these genes permit upstream and downstream modulation of clock pathways as well as growth and inflammation.

\section{Clinical significance of clocks in the developing lung} Introducing the clock to the fetal origins hypothesis presents the notion of fetal programming. Do adult diseases replicate inadequate fetal programming? The Dutch Hunger Winter Study found a significant link between gestational malnutrition and adult cardiovascular and metabolic diseases (153). Many factors can influence fetal development and thereby "program" disease, including uteroplacental blood flow, hypoxia, oxidative stress, malnutrition, and maternal hormones (154). We can speculate that the placenta serves as a gatekeeper to mediate when (in terms of gestational time and/or time of day) and how much of maternal signals (whatever they are) reach the fetus. This may also depend on developmental cues necessary for fetal development. Clock biology is inherently adaptive to its environment, so reasonable speculations can be discussed. The placenta may create a maternal-fetal signaling gradient over gestational time to wean the fetus off maternal cues toward parturition, an effort to prepare the fetus's own adaptive mechanisms for postnatal life. Increased susceptibility to chronic airway diseases in premature infants exposed to insults may reflect inadequate clock establishment or lack of clock programming before birth. Additionally, premature infants in the neonatal ICU experience circadian disruption $(155,156)$, while entrainment strategies improve outcomes (157). If the effect of circadian disruption on the fetal lung is as severe as in the adult, mindfulness of a newborn's developing circadian system may prove beneficial.

Targeting the clock may provide solutions to prevent or treat airway disease progression in premature infants and in those with airway diseases. Multiple mechanisms relevant to airway disease are already associated with clock biology, even if in nonpulmonary tissues (e.g., immune responses, contractility, mitochondrial dynamics, metabolism, senescence pathways). Additionally, the clock is not a two-way street. Many cellular pathways feed into the clock feedback loop, which provides sensing of environmental changes, while core clock components regulate downstream pathways to provide an adaptive advantage. 
This bidirectional relationship highlights the potential benefit of therapeutically targeting the clock (chronotherapeutics), albeit after a more complete understanding of functional roles of the clock in the developing and perinatal lung.

\section{Conclusions}

Understanding of clock biology during fetal and neonatal lung development is currently limited, but holds promise for assessment of mechanisms and potential targets for chronic lung diseases. Substantial insights can be gained from data in other organ systems, and emerging data in adult peripheral lung clocks and lung diseases. Fetal lung clock emergence, synchrony, and function during development add a level of complexity to the circadian field and are a relatively unexplored niche.

\section{Acknowledgments}

This work was supported by NIH grants T32 HL105355 (Bartman), R01 HL056470 (Prakash), and R01 DK098468 (Matveyenko).

Address correspondence to: Y.S. Prakash, 4-184 W Jos SMH, Mayo Clinic, 200 First Street SW, Rochester, Minnesota 55905, USA. Phone: 507.255.7481.Email: prakash.ys@mayo.edu.
1. Takahashi JS. Transcriptional architecture of the mammalian circadian clock. Nat Rev Genet. 2017;18(3):164-179.

2. Stephan FK, Zucker I. Circadian rhythms in drinking behavior and locomotor activity of rats are eliminated by hypothalamic lesions. Proc Natl Acad Sci U S A. 1972;69(6):1583-1586.

3. Moore RY, Eichler VB. Loss of a circadian adrenal corticosterone rhythm following suprachiasmatic lesions in the rat. Brain Res. 1972;42(1):201-206.

4. Newman LA, Walker MT, Brown RL, Cronin TW, Robinson PR. Melanopsin forms a functional short-wavelength photopigment. Biochemistry. 2003;42(44):12734-12738.

5. Konopka RJ, Benzer S. Clock mutants of Drosophila melanogaster. Proc Natl Acad Sci U S A. 1971;68(9):2112-2116.

6. Bargiello TA, Jackson FR, Young MW. Restoration of circadian behavioural rhythms by gene transfer in Drosophila. Nature. 1984;312(5996):752-754.

7. Shin HS, Bargiello TA, Clark BT, Jackson FR, Young MW. An unusual coding sequence from a Drosophila clock gene is conserved in vertebrates. Nature. 1985;317(6036):445-448.

8. Baylies MK, Bargiello TA, Jackson FR, Young MW. Changes in abundance or structure of the per gene product can alter periodicity of the Drosophila clock. Nature. 1987;326(6111):390-392.

9. Ewer J, Rosbash M, Hall JC. An inducible promoter fused to the period gene in Drosophila conditionally rescues adult per-mutant arrhythmicity. Nature. 1988;333(6168):82-84.

10. Yu Q, Colot HV, Kyriacou CP, Hall JC, Rosbash M. Behaviour modification by in vitro mutagenesis of a variable region within the period gene of Drosophila. Nature. 1987;326(6115):765-769.

11. Weaver DR. The suprachiasmatic nucleus: a 25-year retrospective. J Biol Rhythms. 1998;13(2):100-112.

12. Balsalobre A, Damiola F, Schibler U. A serum shock induces circadian gene expression in mammalian tissue culture cells. Cell.1998;93(6):929-937.

13. Nagoshi E, Saini C, Bauer C, Laroche T, Naef F, Schibler U. Circadian gene expression in individual fibroblasts: cell-autonomous and self-sustained oscillators pass time to daughter cells. Cell. 2004;119(5):693-705.

14. Welsh DK, Yoo SH, Liu AC, Takahashi JS, Kay SA. Bioluminescence imaging of individual fibroblasts reveals persistent, independently phased circadian rhythms of clock gene expression. Curr Biol. 2004;14(24):2289-2295.
15. Cuesta M, Cermakian N, Boivin DB. Glucocorticoids entrain molecular clock components in human peripheral cells. FASEB J. 2015;29(4):1360-1370.

16. O'Neill JS, Reddy AB. The essential role of cAMP/ $\mathrm{Ca}^{2+}$ signalling in mammalian circadian timekeeping. Biochem Soc Trans. 2012;40(1):44-50.

17. Bae SA, Androulakis IP. The synergistic role of light-feeding phase relations on entraining robust circadian rhythms in the periphery. Gene Regul Syst Bio. 2017;11:1177625017702393.

18. Buijs FN, Leon-Mercado L, Guzman-Ruiz M, Guerrero-Vargas NN, Romo-Nava F, Buijs RM. The circadian system: a regulatory feedback network of periphery and brain. Physiology (Bethesda). 2016;31(3):170-181.

19. Yoo SH, et al. PERIOD2::LUCIFERASE realtime reporting of circadian dynamics reveals persistent circadian oscillations in mouse peripheral tissues. Proc Natl Acad Sci U S A. 2004;101(15):5339-5346.

20. Medarov BI, Pavlov VA, Rossoff L. Diurnal variations in human pulmonary function. Int J Clin Exp Med. 2008;1(3):267-273.

21. Clark TJ. Diurnal rhythm of asthma. Chest. 1987;91(6 suppl):137S-141S.

22. Clark TJ, Hetzel MR. Diurnal variation of asthma. Br J Dis Chest. 1977;71(2):87-92.

23. Oishi K, Sakamoto K, Okada T, Nagase T, Ishida N. Humoral signals mediate the circadian expression of rat period homologue ( $\mathrm{rPer} 2) \mathrm{mRNA}$ in peripheral tissues. Neurosci Lett.1998;256(2):117-119.

24. O'Neill JS, Maywood ES, Chesham JE, Takahashi JS, Hastings MH. cAMP-dependent signaling as a core component of the mammalian circadian pacemaker. Science. 2008;320(5878):949-953.

25. Lundkvist GB, Kwak Y, Davis EK, Tei H, Block GD. A calcium flux is required for circadian rhythm generation in mammalian pacemaker neurons. J Neurosci. 2005;25(33):7682-7686.

26. Enoki R, Ono D, Kuroda S, Honma S, Honma KI. Dual origins of the intracellular circadian calcium rhythm in the suprachiasmatic nucleus. $\mathrm{Sci}$ Rep. 2017;7:41733.

27. Ikeda M, et al. Circadian dynamics of cytosolic and nuclear $\mathrm{Ca}^{2+}$ in single suprachiasmatic nucleus neurons. Neuron. 2003;38(2):253-263.

28. Doi M, et al. Circadian regulation of intracellular G-protein signalling mediates intercellular synchrony and rhythmicity in the suprachiasmatic nucleus. Nat Commun. 2011;2:327.

29. Li X, et al. CirGRDB: a database for the genomewide deciphering circadian genes and regulators.
Nucleic Acids Res. 2018;46(D1):D64-D70.

30. Mavroudis PD, DuBois DC, Almon RR, Jusko WJ. Modeling circadian variability of core-clock and clock-controlled genes in four tissues of the rat. PLoS One. 2018;13(6):e0197534.

31. Bozek K, et al. Regulation of clock-controlled genes in mammals. PLoS One. 2009;4(3):e4882.

32. Panda S, et al. Coordinated transcription of key pathways in the mouse by the circadian clock. Cell. 2002;109(3):307-320.

33. Hatanaka F, et al. Genome-wide profiling of the core clock protein BMAL1 targets reveals a strict relationship with metabolism. Mol Cell Biol. 2010;30(24):5636-5648.

34. Li S, Zhang L. Circadian control of global transcription. Biomed Res Int. 2015;2015:187809.

35. Chaix A, Zarrinpar A, Panda S. The circadian coordination of cell biology. JCell Biol. 2016;215(1):15-25.

36. Beytebiere JR, et al. Tissue-specific BMAL1 cistromes reveal that rhythmic transcription is associated with rhythmic enhancer-enhancer interactions. Genes Dev. 2019;33(5-6):294-309.

37. Bando H, Nishio T, van der Horst GT, Masubuchi S, Hisa Y, Okamura H. Vagal regulation of respiratory clocks in mice. J Neurosci. 2007;27(16):4359-4365.

38. Sundar IK, Yao H, Sellix MT, Rahman I. Circadian molecular clock in lung pathophysiology. Am J Physiol Lung Cell Mol Physiol. 2015;309(10):L1056-L1075.

39. Sundar IK, Yao H, Sellix MT, Rahman I. Circadian clock-coupled lung cellular and molecular functions in chronic airway diseases. Am J Respir Cell Mol Biol. 2015;53(3):285-290.

40. Evans JA, Davidson AJ. Health consequences of circadian disruption in humans and animal models. Prog Mol Biol Transl Sci. 2013;119:283-323.

41. Gibbs J, et al. An epithelial circadian clock controls pulmonary inflammation and glucocorticoid action. Nat Med. 2014;20(8):919-926.

42. Gibbs JE, et al. The nuclear receptor REV-ERB $\alpha$ mediates circadian regulation of innate immunity through selective regulation of inflammatory cytokines. Proc Natl Acad Sci U S A. 2012;109(2):582-587.

43. Hadden H, Soldin SJ, Massaro D. Circadian disruption alters mouse lung clock gene expression and lung mechanics. J Appl Physiol (1985). 2012;113(3):385-392.

44. Hwang JW, Sundar IK, Yao H, Sellix MT, Rahman I. Circadian clock function is disrupted by environmental tobacco/cigarette smoke, leading to 
lung inflammation and injury via a SIRT1-BMAL1 pathway. FASEB J. 2014;28(1):176-194.

45. Jesudason EC, Keshet E, Warburton D. Entrained pulmonary clocks: epithelium and vasculature keeping pace. Am J Physiol Lung Cell Mol Physiol. 2010;299(4):L453-L454.

46. Pekovic-Vaughan V, et al. The circadian clock regulates rhythmic activation of the NRF2/ glutathione-mediated antioxidant defense pathway to modulate pulmonary fibrosis. Genes Dev. 2014;28(6):548-560.

47. Ehlers A, et al. BMAL1 links the circadian clock to viral airway pathology asthma phenotypes. Mucosal Immunol. 2018;11(1):97-111.

48. Logan RW, et al. Chronic shift-lag alters the circadian clock of NK cells and promotes lung cancer growth in rats. J Immunol. 2012;188(6):2583-2591.

49. Wolff G, Duncan MJ, Esser KA. Chronic phase advance alters circadian physiological rhythms and peripheral molecular clocks. JAppl Physiol (1985). 2013;115(3):373-382.

50. Wu M, et al. Experimental chronic jet lag promotes growth and lung metastasis of Lewis lung carcinoma in C57BL/6 mice. Oncol Rep. 2012;27(5):1417-1428.

51. Nainwal N. Chronotherapeutics - a chronopharmaceutical approach to drug delivery in the treatment of asthma. J Control Release. 2012;163(3):353-360.

52. Herriges M, Morrisey EE. Lung development: orchestrating the generation and regeneration of a complex organ. Development. 2014;141(3):502-513.

53. Nikolic MZ, Sun D, Rawlins EL. Human lung development: recent progress and new challenges. Development. 2018;145(16):dev163485.

54. Domyan ET, Ferretti E, Throckmorton K, Mishina Y, Nicolis SK, Sun X. Signaling through BMP receptors promotes respiratory identity in the foregut via repression of Sox2. Development. 2011;138(5):971-981.

55. Goss AM, et al. Wnt $2 / 2 \mathrm{~b}$ and $\beta$-catenin signaling are necessary sufficient to specify lung progenitors in the foregut. Dev Cell. 2009;17(2):290-298.

56. Harris-Johnson KS, Domyan ET, Vezina CM, Sun $\mathrm{X}$. $\beta$-Catenin promotes respiratory progenitor identity in mouse foregut. Proc Natl Acad Sci US A. 2009;106(38):16287-16292.

57. Sekine K, et al. Fgf10 is essential for limb lung formation. Nat Genet. 1999;21(1):138-141.

58. Ohuchi H, et al. FGF10 acts as a major ligand for FGF receptor 2 IIIb in mouse multi-organ development. Biochem Biophys Res Commun. 2000;277(3):643-649.

59. Bellusci S, Grindley J, Emoto H, Itoh N, Hogan BL. Fibroblast growth factor 10 (FGF10) branching morphogenesis in the embryonic mouse lung. Development. 1997;124(23):4867-4878.

60. Weaver M, Dunn NR, Hogan BL. Bmp4 and Fgf10 play opposing roles during lung bud morphogenesis. Development. 2000;127(12):2695-2704.

61. Que J, Luo X, Schwartz RJ, Hogan BL. Multiple roles for Sox 2 in the developing adult mouse trachea. Development. 2009;136(11):1899-1907.

62. Tompkins DH, et al. Sox2 activates cell proliferation differentiation in the respiratory epithelium. Am J Respir Cell Mol Biol. 2011;45(1):101-110.

63. Faksh A, et al. Effects of antenatal lipopoly- saccharide and postnatal hyperoxia on airway reactivity and remodeling in a neonatal mouse model. Pediatr Res. 2016;79(3):391-400.

64. Reyburn B, et al. The effect of continuous positive airway pressure in a mouse model of hyperoxic neonatal lung injury. Neonatology. 2016;109(1):6-13.

65. Martin YN, et al. Hyperoxia-induced changes in estradiol metabolism in postnatal airway smooth muscle. Am J Physiol Lung Cell Mol Physiol. 2015;308(2):L141-L146.

66. Wang $\mathrm{H}$, et al. Severity of neonatal hyperoxia determines structural and functional changes in developing mouse airway. Am J Physiol Lung Cell Mol Physiol. 2014;307(4):L295-L301.

67. Ko MS, et al. Large-scale cDNA analysis reveals phased gene expression patterns during preimplantation mouse development. Development. 2000;127(8):1737-1749.

68. Johnson MH, Lim A, Fernando D, Day ML. Circadian clockwork genes are expressed in the reproductive tract and conceptus of the early pregnant mouse. Reprod Biomed Online. 2002;4(2):140-145.

69. Kowalska E, Moriggi E, Bauer C, Dibner C, Brown SA. The circadian clock starts ticking at a developmentally early stage. J Biol Rhythms. 2010;25(6):442-449.

70. Paulose JK, Rucker EB 3rd, Cassone VM. Toward the beginning of time: circadian rhythms in metabolism precede rhythms in clock gene expression in mouse embryonic stem cells. PLoS One. 2012;7(11):e49555.

71. Yagita K, et al. Development of the circadian oscillator during differentiation of mouse embryonic stem cells in vitro. Proc Natl Acad Sci U S A. 2010;107(8):3846-3851.

72. Gibb S, Maroto M, Dale JK. The segmentation clock mechanism moves up a notch. Trends Cell Biol. 2010;20(10):593-600.

73. Oates AC, Morelli LG, Ares S. Patterning embryos with oscillations: structure, function and dynamics of the vertebrate segmentation clock. Development. 2012;139(4):625-639.

74. Rida PC, Le Minh N, Jiang YJ. A Notch feeling of somite segmentation and beyond. Dev Biol. 2004;265(1):2-22.

75. Cooke J, Zeeman EC. A clock and wavefront model for control of the number of repeated structures during animal morphogenesis. J Theor Biol. 1976;58(2):455-476.

76. Bessho Y, Hirata H, Masamizu Y, Kageyama R. Periodic repression by the bHLH factor Hes7 is an essential mechanism for the somite segmentation clock. Genes Dev. 2003;17(12):1451-1456.

77. Dale JK, Maroto M, Dequeant ML, Malapert P, McGrew M, Pourquie O. Periodic notch inhibition by lunatic fringe underlies the chick segmentation clock. Nature. 2003;421(6920):275-278.

78. Takashima Y, Ohtsuka T, Gonzalez A, Miyachi H, Kageyama R. Intronic delay is essential for oscillatory expression in the segmentation clock. Proc Natl Acad Sci U S A. 2011;108(8):3300-3305.

79. Masamizu Y, et al. Real-time imaging of the somite segmentation clock: revelation of unstable oscillators in the individual presomitic mesoderm cells. Proc Natl Acad Sci U S A. 2006;103(5):1313-1318.

80. Aulehla A, et al. A $\beta$-catenin gradient links the clock and wavefront systems in mouse embryo segmentation. Nat Cell Biol. 2008;10(2):186-193.

81. Curran KL, et al. Circadian genes, xBmal1 and xNocturnin, modulate the timing differentiation of somites in Xenopus laevis. PLoS One. 2014;9(9):e108266.

82. Curran KL, et al. Circadian genes are expressed during early development in Xenopus laevis. PLoS One. 2008;3(7):e2749.

83. Andrews JL, et al. CLOCK and BMAL1 regulate MyoD are necessary for maintenance of skeletal muscle phenotype function. Proc Natl Acad Sci U S A. 2010;107(44):19090-19095.

84. Chatterjee S, et al. Brain and muscle Arnt-like 1 is a key regulator of myogenesis. JCell Sci. 2013;126(pt 10):2213-2224.

85. Lowe $\mathrm{M}$, et al. Cry2 is critical for circadian regulation of myogenic differentiation by Bclaf1-mediated mRNA stabilization of cyclin D1 Tmem176b. Cell Rep. 2018;22(8):2118-2132.

86. Chatterjee S, Yin H, Li W, Lee J, Yechoor VK, $\mathrm{Ma} \mathrm{K}$. The nuclear receptor and clock repressor Rev-erbalpha suppresses myogenesis. Sci Rep. 2019;9(1):4585

87. Saxena MT, et al. Bioluminescence imaging of period1 gene expression in utero. Mol Imaging. 2007;6(1):68-72.

88. Gonzales LW, Guttentag SH, Wade KC, Postle AD, Ballard PL. Differentiation of human pulmonary type II cells in vitro by glucocorticoid plus cAMP. Am J Physiol Lung Cell Mol Physiol. 2002;283(5):L940-L951.

89. Kang Y, Hebron H, Ozbun L, Mariano J, Minoo P, Jakowlew SB. Nkx2.1 transcription factor in lung cells a transforming growth factor-beta1 heterozygous mouse model of lung carcinogenesis. Mol Carcinog. 2004;40(4):212-231.

90. Berhane K, Margana RK, Boggaram V. Characterization of rabbit SP-B promoter region responsive to downregulation by tumor necrosis factor-alpha. Am J Physiol Lung Cell Mol Physiol. 2000;279(5):L806-L814.

91. Boggaram V. Thyroid transcription factor-1 (TTF1/Nkx2.1/TITF1) gene regulation in the lung. Clin Sci (Lond). 2009;116(1):27-35.

92. Matagne V, et al. Thyroid transcription factor 1 , a homeodomain containing transcription factor, contributes to regulating periodic oscillations in GnRH gene expression. J Neuroendocrinol. 2012;24(6):916-929.

93. Kim MS, et al. Regulation of pituitary adenylate cyclase-activating polypeptide gene transcription by TTF-1, a homeodomain-containing transcription factor. J Biol Chem. 2002;277(39):36863-36871.

94. Tagne JB, et al. Genome-wide analyses of Nkx2-1 binding to transcriptional target genes uncover novel regulatory patterns conserved in lung development and tumors. PLoS One. 2012;7(1):e29907.

95. Yi M, Tong GX, Murry B, Mendelson CR. Role of $\mathrm{CBP} / \mathrm{p} 300$ and SRC-1 in transcriptional regulation of the pulmonary surfactant protein-A (SPA) gene by thyroid transcription factor-1 (TTF-1). J Biol Chem. 2002;277(4):2997-3005.

96. Parasram K, et al. Intestinal stem cells exhibit conditional circadian clock function. Stem Cell Reports. 2018;11(5):1287-1301.

97. Sun S, Zhou L, Yu Y, Zhang T, Wang M. Knock- 
ing down clock control gene CRY1 decreases adipogenesis via canonical Wnt/ $\beta$-catenin signaling pathway. Biochem Biophys Res Commun. 2018;506(3):746-753.

98. Zhu Z, et al. CLOCK promotes 3T3-L1 cell proliferation via Wnt signaling. IUBMB Life. 2016;68(7):557-568.

99. Zhou L, Zhang T, Sun S, Yu Y, Wang M. Cryptochrome 1 promotes osteogenic differentiation of human osteoblastic cells via Wnt/ $\beta$-catenin signaling. Life Sci. 2018;212:129-137.

100.Zhu M, Tang H, Tang X, Ma X, Guo D, Chen F. BMAL1 suppresses ROS-induced endothelial-to-mesenchymal transition atherosclerosis plaque progression via BMP signaling. Am J Transl Res. 2018;10(10):3150-3161.

101. Tasaki $\mathrm{H}$, et al. Inhibitory role of REV-ERBalpha in the expression of bone morphogenetic protein gene family in rat uterus endometrium stromal cells. $A m$ JPhysiol Cell Physiol. 2015;308(7):C528-C538.

102. Moura RS, Carvalho-Correia E, daMota P, Correia-Pinto J. Canonical Wnt signaling activity in early stages of chick lung development. PLOS One. 2014;9(12):e112388.

103. Cohen JC, Larson JE, Killeen E, Love D, Takemaru K. CFTR and Wnt/beta-catenin signaling in lung development. BMC Dev Biol. 2008;8:70.

104.Shu W, Jiang YQ, Lu MM, Morrisey EE. Wnt7b regulates mesenchymal proliferation and vascular development in the lung. Development. 2002;129(20):4831-4842.

105. Yun EJ, Vu TH. mSmile is necessary for bronchial smooth muscle and alveolar myofibroblast development. Anat Rec (Hoboken). 2012;295(1):167-176

106.Zhang XQ, et al. Regulation of pulmonary surfactant synthesis in fetal rat type II alveolar epithelial cells by microRNA-26a. Pediatr Pulmonol. 2014;49(9):863-872.

107. Southwood M, et al. Regulation of bone morphogenetic protein signalling in human pulmonary vascular development. JPathol. 2008;214(1):85-95.

108. Shi W, Zhao J, Anderson KD, Warburton D. Gremlin negatively modulates BMP-4 induction of embryonic mouse lung branching morphogenesis. Am J Physiol Lung Cell Mol Physiol. 2001;280(5):L1030-L1039.

109.Gebb SA, Jones PL. Hypoxia and lung branching morphogenesis. Adv Exp Med Biol. 2003;543:117-125.

110. Kotch LE, Iyer NV, Laughner E, Semenza GL. Defective vascularization of HIF-1alpha-null embryos is not associated with VEGF deficiency but with mesenchymal cell death. Dev Biol. 1999;209(2):254-267.

111. Hu CJ, Wang LY, Chodosh LA, Keith B, Simon MC. Differential roles of hypoxia-inducible factor 1alpha (HIF-1 $\alpha$ ) HIF-2alpha in hypoxic gene regulation. Mol Cell Biol. 2003;23(24):9361-9374.

112. Wenger RH, Stiehl DP, Camenisch G. Integration of oxygen signaling at the consensus HRE. Sci STKE. 2005;2005(306):re12.

113. Wu Y, et al. Reciprocal regulation between the circadian clock and hypoxia signaling at the genome level in mammals. Cell Metab. 2017;25(1):73-85.

114. Wu D, Rastinejad F. Structural characterization of mammalian bHLH-PAS transcription factors. Curr Opin Struct Biol. 2017;43:1-9.
115. Peek CB, et al. Circadian clock interaction with HIF1alpha mediates oxygenic metabolism and anaerobic glycolysis in skeletal muscle. Cell Metab. 2017;25(1):86-92.

116. Adamovich Y, Ladeuix B, Golik M, Koeners MP, Asher G. Rhythmic oxygen levels reset circadian clocks through HIF1a. Cell Metab. 2017;25(1):93-101.

117. Joseph V, Mamet J, Lee F, Dalmaz Y, Van Reeth O. Prenatal hypoxia impairs circadian synchronisation and response of the biological clock to light in adult rats. JPhysiol. 2002;543(pt 1):387-395.

118. Chen L, Yang G. PPARs integrate the mammalian clock and energy metabolism. PPAR Res. 2014;2014:653017.

119. Seron-Ferre M, Riffo R, Valenzuela GJ, Germain AM. Twenty-four-hour pattern of cortisol in the human fetus at term. Am JObstet Gynecol. 2001;184(6):1278-1283.

120.Patrick J, Challis J, Campbell K, Carmichael L, Richardson B, Tevaarwerk G. Effects of synthetic glucocorticoid administration on human fetal breathing movements at 34 to 35 weeks' gestational age. Am J Obstet Gynecol.1981;139(3):324-328.

121. Lunshof S, Boer K, Wolf H, van Hoffen G, Bayram N, Mirmiran M. Fetal and maternal diurnal rhythms during the third trimester of normal pregnancy: outcomes of computerized analysis of continuous twenty-four-hour fetal heart rate recordings. $\mathrm{Am} J$ Obstet Gynecol. 1998;178(2):247-254.

122. de Vries JI, Visser GH, Mulder EJ, Prechtl HF. Diurnal and other variations in fetal movement and heart rate patterns at 20-22 weeks. Early Hum Dev. 1987;15(6):333-348.

123. Viswanathan N, Weaver DR, Reppert SM, Davis FC. Entrainment of the fetal hamster circadian pacemaker by prenatal injections of the dopamine agonist SKF 38393. J Neurosci. 1994;14(9):5393-5398.

124. Davis FC, Gorski RA. Development of hamster circadian rhythms: role of the maternal suprachiasmatic nucleus. J Comp Physiol A. 1988;162(5):601-610.

125. Reppert SM, Schwartz WJ. Maternal suprachiasmatic nuclei are necessary for maternal coordination of the developing circadian system. J Neurosci. 1986;6(9):2724-2729.

126. Jud C, Albrecht U. Circadian rhythms in murine pups develop in absence of a functional maternal circadian clock. JBiol Rhythms. 2006;21(2):149-154.

127. Davis FC, Mannion J. Entrainment of hamster pup circadian rhythms by prenatal melatonin injections to the mother. Am J Physiol. 1988;255(3 pt 2):R439-R448.

128. Mendez N, et al. Timed maternal melatonin treatment reverses circadian disruption of the fetal adrenal clock imposed by exposure to constant light. PLoS One. 2012;7(8):e42713.

129. Oster $\mathrm{H}$, et al. The circadian rhythm of glucocorticoids is regulated by a gating mechanism residing in the adrenal cortical clock. Cell Metab. 2006;4(2):163-173.

130. Son GH, et al. Adrenal peripheral clock controls the autonomous circadian rhythm of glucocorticoid by causing rhythmic steroid production. Proc Natl Acad Sci U S A. 2008;105(52):20970-20975.

131. Levi F, Schibler U. Circadian rhythms: mechanisms and therapeutic implications. Annu Rev
Pharmacol Toxicol. 2007;47:593-628.

132. Bolt RJ, van Weissenbruch MM, Lafeber HN, Delemarre-van de Waal HA. Glucocorticoids and lung development in the fetus and preterm infant. Pediatr Pulmonol. 2001;32(1):76-91.

133. Orgeig S, McGillick EV, Botting KJ, Zhang S, McMillen IC, Morrison JL. Increased lung prolyl hydroxylase and decreased glucocorticoid receptor are related to decreased surfactant protein in the growth-restricted sheep fetus. Am J Physiol Lung Cell Mol Physiol. 2015;309(1):L84-L97.

134. Mark PJ, Crew RC, Wharfe MD, Waddell BJ. Rhythmic three-part harmony: the complex interaction of maternal, placental and fetal circadian systems. JBiol Rhythms. 2017;32(6):534-549.

135. Balsalobre A, et al. Resetting of circadian time in peripheral tissues by glucocorticoid signaling. Science. 2000;289(5488):2344-2347.

136. Barker DJ. The fetal and infant origins of adult disease. BMJ.1990;301(6761):1111.

137. Barker DJ. The fetal and infant origins of disease Eur JClin Invest. 1995;25(7):457-463.

138. Calkins K, Devaskar SU. Fetal origins of adult disease. Curr Probl Pediatr Adolesc Health Care. 2011;41(6):158-176.

139. Kondratov RV, Kondratova AA, Gorbacheva VY, Vykhovanets OV, Antoch MP. Early aging and age-related pathologies in mice deficient in BMAL1, the core componentof the circadian clock. Genes Dev. 2006;20(14):1868-1873.

140. Kennaway DJ. The role of circadian rhythmicity in reproduction. Hum Reprod Update. 2005;11(1):91-101.

141. Kondratov RV, Vykhovanets O, Kondratova AA, Antoch MP. Antioxidant N-acetyl-L-cysteine ameliorates symptoms of premature aging associated with the deficiency of the circadian protein BMAL1. Aging (Albany NY). 2009;1(12):979-987.

142.Yang G, et al. Timing of expression of the core clock gene Bmal1 influences its effects on aging survival. Sci Transl Med. 2016;8(324):324ra16.

143. Hillman NH, Kallapur SG, Jobe AH. Physiology of transition from intrauterine to extrauterine life. Clin Perinatol. 2012;39(4):769-783.

144. Bookout AL, Jeong Y, Downes M, Yu RT, Evans RM, Mangelsdorf DJ. Anatomical profiling of nuclear receptor expression reveals a hierarchical transcriptional network. Cell. 2006;126(4):789-799.

145. Vasu VT, Cross CE, Gohil K. Nr1d1, an important circadian pathway regulatory gene, is suppressed by cigarette smoke in murine lungs. Integr Cancer Ther. 2009;8(4):321-328.

146.Yang G, Abate A, George AG, Weng YH, Dennery PA. Maturational differences in lung NF- $\mathrm{KB}$ activation and their role in tolerance to hyperoxia. $J$ Clin Invest. 2004;114(5):669-678.

147. Yang $\mathrm{G}$, et al. Oxidative stress and inflammation modulate Rev-erb $\alpha$ signaling in the neonatal lung and affect circadian rhythmicity. Antioxid Redox Signal. 2014;21(1):17-32.

148. Yang G, et al. Silencing hyperoxia-induced C/ EBP $\propto$ in neonatal mice improves lung architecture via enhanced proliferation of alveolar epithelial cells. Am J Physiol Lung Cell Mol Physiol. 2011;301(2):L187-L196.

149. Martis PC, Whitsett JA, Xu Y, Perl AK, Wan H, Ikegami M. C/EBPa is required for lung maturation at birth. Development. 2006;133(6):1155-1164. 
150. Gery S, Gombart AF, Yi WS, Koeffler C, Hofmann WK, Koeffler HP. Transcription profiling of C/ EBP targets identifies Per2 as a gene implicated in myeloid leukemia. Blood. 2005;106(8):2827-2836.

151. Thoennissen NH, et al. Transcription factor CCAAT/enhancer-binding protein $\alpha$ and critical circadian clock downstream target gene PER2 are highly deregulated in diffuse large B-cell lymphoma. Leuk Lymphoma. 2012;53(8):1577-1585.

152. Ardini-Poleske ME, et al. LungMAP: the molecular atlas of lung development program. Am JPhysiol Lung Cell Mol Physiol. 2017;313(5):L733-LL40.

153. Roseboom T, de Rooij S, Painter R. The Dutch famine and its long-term consequences for adult health. Early Hum Dev. 2006;82(8):485-491.

154. Kwon EJ, Kim YJ. What is fetal programming?: a lifetime health is under the control of in utero health. Obstet Gynecol Sci. 2017;60(6):506-519.

155. Bueno C, Menna-Barreto L. Environmental factors influencing biological rhythms in newborns: from neonatal intensive care units to home. Sleep Sci. 2016;9(4):295-300.

156. Rea MS, Figueiro MG. The NICU lighted environment. Newborn Infant Nurs Rev. 2016;16(4):195-202.

157. Vasquez-Ruiz S, et al. A light/dark cycle in the NICU accelerates body weight gain and shortens time to discharge in preterm infants. Early Hum Dev. 2014;90(9):535-540.

158. Truong KK, Lam MT, Grandner MA, Sassoon CS, Malhotra A. Timing matters: circadian rhythm in sepsis, obstructive lung disease, obstructive sleep apnea, and cancer. Ann Am Thorac Soc. 2016;13(7):1144-1154.

159. Barnes PJ. Circadian variation in airway function. AmJMed.1985;79(6A):5-9.

160.Zaslona $\mathrm{Z}$, et al. The circadian protein BMAL1 in myeloid cells is a negative regulator of allergic asthma. Am J Physiol Lung Cell Mol Physiol. 2017;312(6):L855-LL60.

161. Sengupta S, et al. Circadian control of lung inflammation in influenza infection. Nat Commun. 2019;10(1):4107.

162.Yeom M, Lee H, Shin S, Park D, Jung E. PER, a circadian clock component, mediates the suppression of MMP-1 expression in $\mathrm{HaCaT}$ keratinocytes by cAMP. Molecules. 2018;23(4):E745

163. Khapre RV, Samsa WE, Kondratov RV. Circadian regulation of cell cycle: molecular connections between aging and the circadian clock. Ann Med. 2010;42(6):404-415.

164.Early JO, et al. Circadian clock protein BMAL1 regulates IL-1beta in macrophages via NRF2. Proc Natl Acad Sci U S A. 2018;115(36):E8460-E84E8.

165. Dong C, Gongora R, Sosulski ML, Luo F, Sanchez CG. Regulation of transforming growth factorbeta1 (TGF- $\beta 1$ )-induced pro-fibrotic activities by circadian clock gene BMAL1. Respir Res. 2016;17:4.

166. Khapre RV, et al. BMAL1-dependent regulation of the $\mathrm{mTOR}$ signaling pathway delays aging. Aging (Albany NY). 2014;6(1):48-57.

167. Papagiannakopoulos T, et al. Circadian rhythm disruption promotes lung tumorigenesis. Cell Metab. 2016;24(2):324-331.

168. Ikeda M, Ikeda M. Bmal1 is an essential regulator for circadian cytosolic $\mathrm{Ca}(2)(+)$ rhythms in suprachiasmatic nucleus neurons. J Neurosci. 2014;34(36):12029-12038.

169. Morioka E, Kanda Y, Koizumi H, Miyamoto T, Ikeda M. Histamine regulates molecular clock oscillations in human retinal pigment epithelial cells via H1 receptors. Front Endocrinol (Lausanne). 2018;9:108.

170.Boucher H, Vanneaux V, Domet T, Parouchev A, Larghero J. Circadian clock genes modulate human bone marrow mesenchymal stem cell differentiation, migration and cell cycle. PLoS One. 2016;11(1):e0146674.

171. Janich P, et al. Human epidermal stem cell function is regulated by circadian oscillations. Cell Stem Cell. 2013;13(6):745-753.

172. Malik A, Kondratov RV, Jamasbi RJ, Geusz ME. Circadian clock genes are essential for normal adult neurogenesis, differentiation, and fate determination. PLoS One. 2015;10(10):e0139655

173. Jacobi D, et al. Hepatic Bmal1 regulates rhythmic mitochondrial dynamics and promotes metabolic fitness. Cell Metab. 2015;22(4):709-720.

174. Anafi RC, Francey LJ, Hogenesch JB, Kim J. CYCLOPS reveals human transcriptional rhythms in health and disease. Proc Natl Acad Sci US A. 2017;114(20):5312-5317.

175.Sundar IK, Sellix MT, Rahman I. Redox regulation of circadian molecular clock in chronic airway diseases. Free Radic Biol Med. 2018;119:121-128.

176. McNicholas WT, Fitzgerald MX. Nocturnal deaths among patients with chronic bronchitis and emphysema. Br Med J (Clin Res Ed). 1984;289(6449):878.

177. Petty TL. Circadian variations in chronic asthma and chronic obstructive pulmonary disease. $A m J$ Med.1988;85(1B):21-23.

178. Tirlapur VG. Nocturnal deaths among patients with chronic bronchitis and emphysema. $\mathrm{Br}$ Med $J($ Clin Res Ed). 1984;289(6457):1540.

179. Traves SL, Proud D. Viral-associated exacerbations of asthma and COPD. Curr Opin Pharmacol. 2007;7(3):252-258.

180. Burioka N. [Chronotherapy of bronchial asthma] (article in Japanese). Nihon Rinsho. 2013;71(12):2146-2152.

181. Sutherland ER. Nocturnal asthma. JAllergy Clin
Immunol. 2005;116(6):1179-1186.

182.Asher G, et al. SIRT1 regulates circadian clock gene expression through PER2 deacetylation. Cell. 2008;134(2):317-328.

183. Cho HY, Reddy SP, Kleeberger SR. Nrf2 defends the lung from oxidative stress. Antioxid Redox Signal. 2006;8(1-2):76-87.

184. Hayes JD, McMahon M. NRF2 and KEAP1 mutations: permanent activation of an adaptive response in cancer. Trends Biochem Sci. 2009;34(4):176-188.

185. Chan K, Kan YW. Nrf2 is essential for protection against acute pulmonary injury in mice. Proc Natl Acad Sci U S A. 1999;96(22):12731-12736.

186.Rajendrasozhan S, Yang SR, Kinnula VL, Rahman I. SIRT1, an antiinflammatory and antiaging protein, is decreased in lungs of patients with chronic obstructive pulmonary disease. Am J Respir Crit Care Med. 2008;177(8):861-870.

187. Yang SR, Wright J, Bauter M, Seweryniak K, Kode A, Rahman I. Sirtuin regulates cigarette smoke-induced proinflammatory mediator release via RelA/p65 NF-kappaB in macrophages in vitro in rat lungs in vivo: implications for chronic inflammation aging. Am J Physiol Lung Cell Mol Physiol. 2007;292(2):L567-L576.

188. Majumdar T, Dhar J, Patel S, Kondratov R, Barik S. Circadian transcription factor BMAL1 regulates innate immunity against select RNA viruses. Innate Immun. 2017;23(2):147-154.

189.Zhang Z, et al. Genome-wide effect of pulmonary airway epithelial cell-specific Bmal1 deletion. FASEB J. 2019;33(5):6226-6238.

190.Sundar IK, et al. Influenza A virus-dependent remodeling of pulmonary clock function in a mouse model of COPD. Sci Rep. 2015;4:9927.

191.Lagishetty V, et al. Dysregulation of CLOCK gene expression in hyperoxia-induced lung injury. Am J Physiol Cell Physiol. 2014;306(11):C999-C1007.

192.DeBruyne JP, Weaver DR, Reppert SM. Peripheral circadian oscillators require CLOCK. Curr Biol. 2007;17(14):R538-R539.

193. Pendergast JS, Friday RC, Yamazaki S. Distinct functions of Period 2 and Period 3 in the mouse circadian system revealed by in vitro analysis. PLoS One. 2010;5(1):e8552.

194. Sundar IK, Rashid K, Sellix MT, Rahman I. The nuclear receptor and clock gene REV-ERBalpha regulates cigarette smoke-induced lung inflammation. Biochem Biophys Res Commun . 2017;493(4):1390-1395.

195.Sukumaran S, Jusko WJ, Dubois DC, Almon RR. Light-dark oscillations in the lung transcriptome: implications for lung homeostasis, repair, metabolism, disease, and drug action. JAppl Physiol (1985). 2011;110(6):1732-1747. 